\title{
Position of the hyoid bone and its correlation with airway dimensions in different classes of skeletal malocclusion using cone-beam computed tomography
}

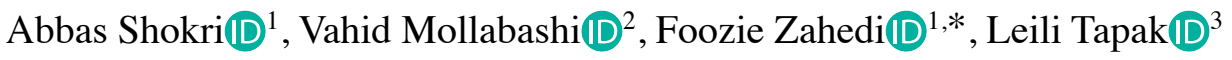 \\ ${ }^{1}$ Dental Implant Research Center, Department of Oral and Maxillofacial Radiology, Dental School, Hamadan University of Medical \\ Sciences, Hamadan, Iran \\ ${ }^{2}$ Department of Orthodontics, Dental School, Dental Research Center, Hamadan University of Medical Sciences, Hamadan, Iran \\ ${ }^{3}$ Department of Biostatistics, School of Public Health, Hamadan University of Medical Sciences, Hamadan, Iran
}

\section{ABSTRACT}

Purpose: This study investigated the position of the hyoid bone and its relationship with airway dimensions in different skeletal malocclusion classes using cone-beam computed tomography (CBCT).

Materials and Methods: CBCT scans of 180 participants were categorized based on the A point-nasion-B point angle into class I, class II, and class III malocclusions. Eight linear and 2 angular hyoid parameters (H-C3, H-EB, H-PNS, $\mathrm{H}-\mathrm{Me}, \mathrm{H}-\mathrm{X}, \mathrm{H}-\mathrm{Y}, \mathrm{H}-[\mathrm{C} 3-\mathrm{Me}], \mathrm{C} 3-\mathrm{Me}, \mathrm{H}-\mathrm{S}-\mathrm{Ba}$, and $\mathrm{H}-\mathrm{N}-\mathrm{S}$ ) were measured. A 3-dimensional airway model was designed to measure the minimum cross-sectional area, volume, and total and upper airway length. The mean crosssectional area, morphology, and location of the airway were also evaluated. Data were analyzed using analysis of variance and the Pearson correlation test, with $P$ values $<0.05$ indicating statistical significance.

Results: The mean airway volume differed significantly among the malocclusion classes $(P<0.05)$. The smallest and largest volumes were noted in class II $\left(2107.8 \pm 844.7 \mathrm{~mm}^{3}\right)$ and class III $\left(2826.6 \pm 2505.3 \mathrm{~mm}^{3}\right)$, respectively. The means of most hyoid parameters (C3-Me, C3-H, H-Eb, H-Me, H-S-Ba, H-N-S, and H-PNS) differed significantly among the malocclusion classes. In all classes, $\mathrm{H}$-Eb was correlated with the minimum cross-sectional area and airway morphology, and H-PNS was correlated with total airway length. A significant correlation was also noted between $\mathrm{H}-\mathrm{Y}$ and total airway length in class II and III malocclusions and between H-Y and upper airway length in class I malocclusions.

Conclusion: The position of the hyoid bone was associated with airway dimensions and should be considered during orthognathic surgery due to the risk of airway obstruction.(Imaging Sci Dent 2020; 50: 105-15)

KEY WORDS: Hyoid Bone; Correlation of Data; Airway Management; Malocclusion; Cone-Beam Computed Tomography

\section{Introduction}

The development and proper functioning of the nasal cavity, nasopharynx, and oropharynx are interconnected with the normal growth pattern of the maxillofacial complex. Significant relationships have been reported between pharyngeal and dentocraniofacial structures. ${ }^{1}$ Upper airway dimensions play a critical role in the airway obstruction

Received October 19, 2019; Revised February 13, 2020; Accepted March 14, 2020 *Correspondence to : Dr. Foozie Zahedi

Department of Oral and Maxillofacial Radiology, Dental School, Hamadan University of Medical Sciences, Shahid Fahmideh St, Hamadan 654178-38741, Iran Tel) 98-918-318-5767, E-mail) fooziezahedi@yahoo.com and collapse that cause obstructive sleep apnea.,

Evidence shows that the craniofacial skeletal morphology may affect nasal respiratory function and the upper airway. Nasal airflow and nasal resistance are significantly higher in patients with skeletal class III malocclusion than in individuals with class I or class II malocclusion. ${ }^{4}$ Certain skeletal characteristics, such as maxillary and mandibular retrusion or vertical maxillary excess in hyperdivergent patients, may be associated with smaller airway dimensions. ${ }^{5}$ Patients with obstructive sleep apnea have lower pharyngeal resistance to collapse, and lateral and posterior wall collapse is also common among these patients. ${ }^{6}$

Recent investigations have revealed that individuals with

Copyright (c) 2020 by Korean Academy of Oral and Maxillofacial Radiology

This is an Open Access article distributed under the terms of the Creative Commons Attribution Non-Commercial License (http://creativecommons.org/licenses/by-nc/3.0) which permits unrestricted non-commercial use, distribution, and reproduction in any medium, provided the original work is properly cited. Imaging Science in Dentistry · pISSN 2233-7822 eISSN 2233-7830 
class II malocclusion have narrower and smaller airways than those with class III malocclusion. ${ }^{7}$ Mandibular setback retracts the hyoid bone and narrows the airway. ${ }^{8,9}$

The hyoid is a $\mathrm{U}$-shaped bone located above the larynx and inferior to the base of the skull. It is connected to the posterior mandible and cranium by muscles and ligaments. ${ }^{10}$ The hyoid bone plays a critical role in balancing the tension of the anterior and posterior occipital condyle muscles, leading to correct positioning of the head when standing. A significant correlation has been reported between changes in the posterior airway space and the hyoid bone position after mandibular advancement surgery. ${ }^{11}$ As such, the position of the hyoid bone seems to affect the airway and should be considered in orthodontic diagnosis and treatment planning. ${ }^{12}$

Most previous studies have used lateral cephalograms to assess correlations between airway dimensions and the hyoid bone or skeletal patterns. ${ }^{13-17}$ Although lateral cephalograms can provide valuable information, they have limitations inherent to the 2-dimensional (2D) visualization of 3-dimensional (3D) structures. Cone-beam computed tomography $(\mathrm{CBCT})$ is a $3 \mathrm{D}$ imaging modality that provides high-quality images in the axial, coronal, and sagittal planes. ${ }^{12,18,19}$

Therefore, this study was performed to evaluate the position of the hyoid bone and its correlation with airway dimensions in different skeletal classes of malocclusion using CBCT.

\section{Materials and Methods}

This cross-sectional study evaluated 180 CBCT images of patients (118 women and 62 men) retrieved from the archives of the Dental School of Hamadan University of Medical Sciences. The images were originally taken between 2011 and 2018. Sample size was determined using PASS software v. 11 (NCSS LLC, Kaysville, UT, USA) for correlation studies. Assuming a study power of $80 \%$, a level of significance of 0.05 , and an attrition rate of $10 \%$, we calculated a sample size of 52 for each group.

First, 556 CBCT scans retrieved from the university archives (from the period between 2011 and 2018) were observed by an examiner. According to the eligibility criteria, 180 images were selected using convenience sampling and were included in the study. The malocclusion class of the patient was determined on each CBCT image. According to the CBCT image analysis, the numbers of class I, class II, and class III patients were 52, 66, and 62, respectively. This study was approved by the ethics committee of

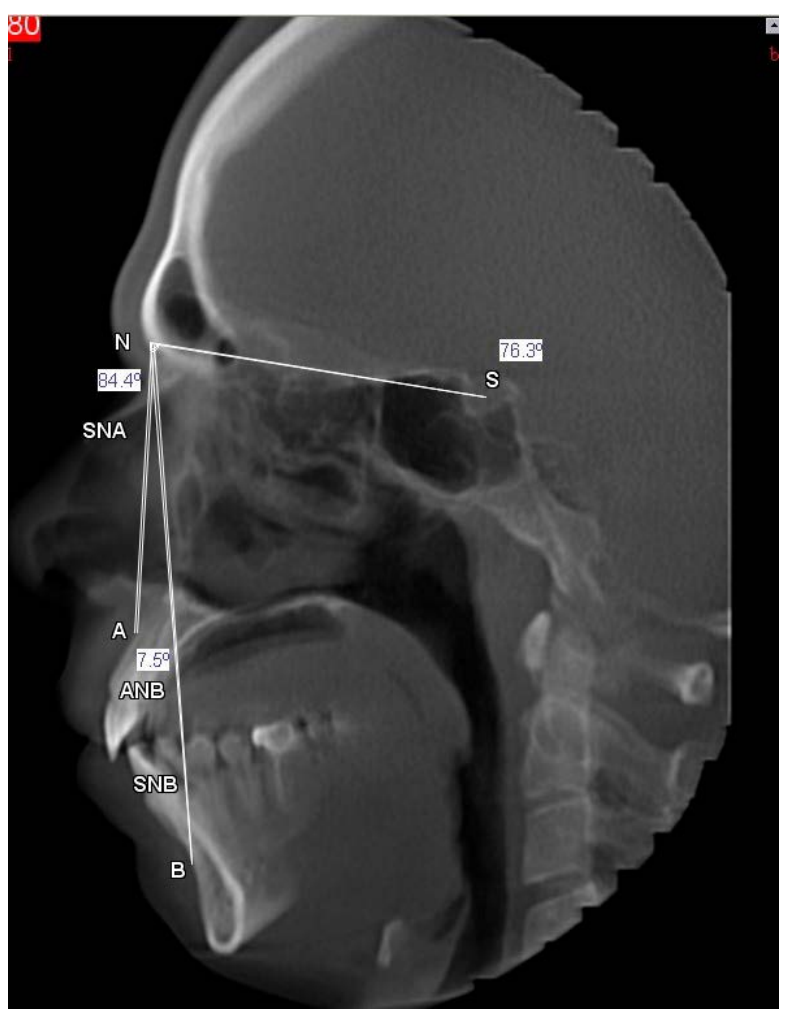

Fig. 1. SNA, SNB, and ANB angles are marked and calculated in order to determine the patient's malocclusion class. SNA: sella-nasion-A point, SNB: sella-nasion-B point, ANB: A point-nasion-B point.

Hamadan University of Medical Sciences (IR.UMSHA. REC.1396.619).

The inclusion criteria included an age of at least 18 years to ensure that growth and development had completed. To be included, the CBCT images must have been taken with a $13 \mathrm{~cm} \times 16 \mathrm{~cm}$ field of view and a $0.3-\mathrm{mm}$ voxel size, and the fourth cervical vertebra $(\mathrm{C} 4)$ had to be visible. For imaging, the patients were in the supine position with the head and spine aligned. The head was rested on a foam pillow, keeping the neck in a neutral position, and was supported by a headrest. Each patient was asked to swallow once before exposure, hold his or her breath during the procedure, and close his or her mouth in maximum intercuspation occlusion. The exclusion criteria were pathological conditions of the pharynx, nasal obstruction, and a history of major orthodontic treatment.

The CBCT images were captured with a NewTom 3G CBCT system (QR srl, Verona, Italy) with exposure settings of $110 \mathrm{kVp}$ and $3.2 \mathrm{~mA}$. The images were archived in the Digital Imaging and Communications in Medicine format.

Reconstructed lateral cephalometric images were ob- 

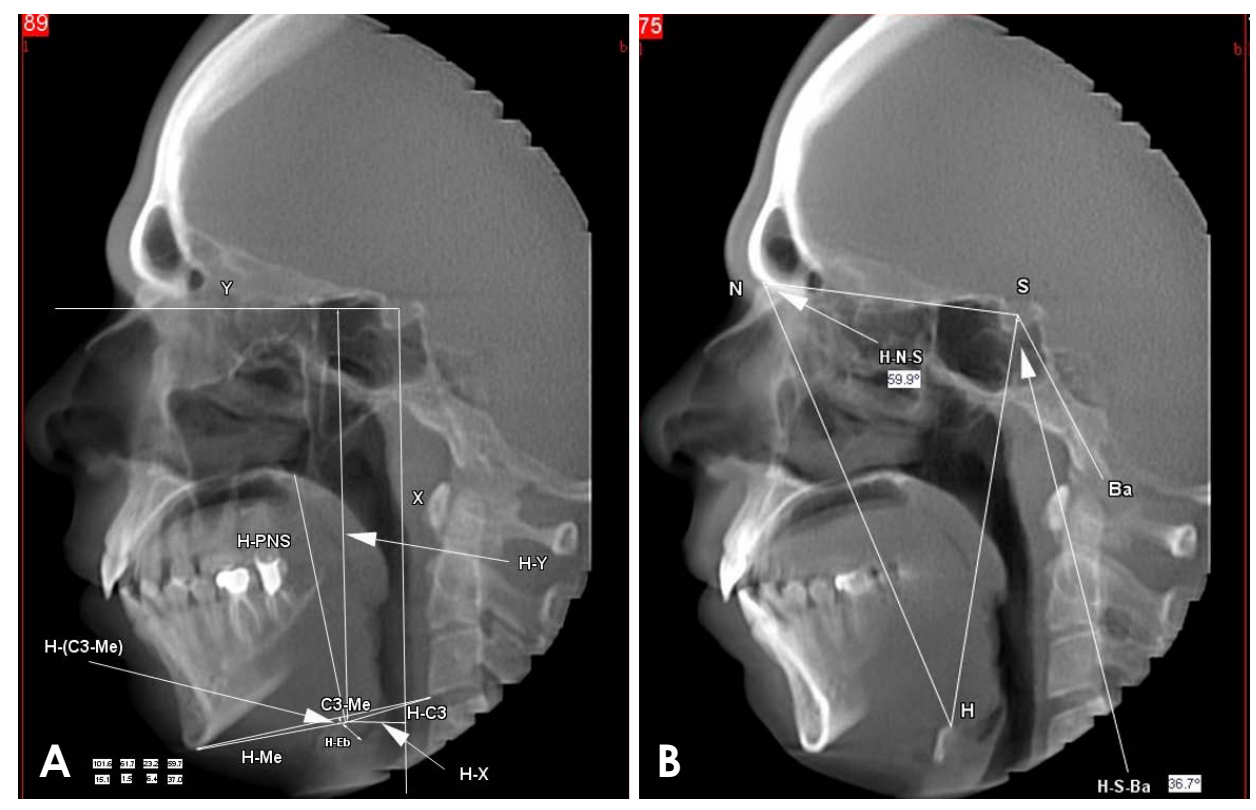

Fig. 2. A. Eight linear (C3-Me, $\mathrm{H}-\mathrm{Me}, \mathrm{H}-\mathrm{C} 3, \mathrm{H}-\mathrm{EB}, \mathrm{H}-(\mathrm{C} 3-\mathrm{Me})$, $\mathrm{H}-\mathrm{PNS}, \mathrm{H}-\mathrm{Y}$, and $\mathrm{H}-\mathrm{X}$ ) hyoid parameters are marked and calculated on the reconstructed lateral cephalogram. B. Two angular (H-N-S and $\mathrm{H}-\mathrm{s}-\mathrm{Ba}$ ) hyoid parameters are marked and calculated on the reconstructed lateral cephalogram.

Table 1. Cephalometric points used to measure hyoid parameters and the A point-nasion-B point (ANB) angle

\begin{tabular}{|c|c|}
\hline Parameter & Definition \\
\hline S & Sella \\
\hline $\mathrm{N}$ & Nasion \\
\hline $\mathrm{Ba}$ & Basion \\
\hline A point & The deepest anterior point in the buccal surface of the body of the maxilla \\
\hline B point & The deepest anterior point in the buccal surface of the body of the mandible \\
\hline $\mathrm{Me}$ & Menton \\
\hline ANS & Anterior nasal spine \\
\hline $\mathrm{Eb}$ & The base of the epiglottis \\
\hline $\mathrm{H}$ & The highest point of the hyoid bone \\
\hline $\mathrm{C} 3$ & The most anteroinferior point on the corpus of the third cervical vertebra \\
\hline Но & Hormion: the most posterior midline point on the vomer \\
\hline Total airway length & The distance from the hard palate to the base of the epiglottis \\
\hline Upper airway length & $\begin{array}{l}\text { The distance between the upper border of the lower part of the pharynx and the point of minimum cross- } \\
\text { sectional area of the airway }\end{array}$ \\
\hline Airway volume & $\begin{array}{l}\text { Region confined by } 3 \text { points (hormion, PNS, basion) and the line passing through the most } \\
\text { anterosuperior point of } \mathrm{C}_{4} \text { and the posterior wall of the pharynx, parallel to the Frankfort plane }\end{array}$ \\
\hline Morphology & Defined as the ratio of the minimum cross-sectional area of the airway to the mean cross-sectional area \\
\hline Location & Defined as the ratio of upper airway length to total airway length \\
\hline Mean cross-sectional area & Defined as the ratio of airway volume to airway length \\
\hline Minimum cross-sectional area & Measured with Autodesk Meshmixer v. 3.0 3-dimensional analytical software \\
\hline
\end{tabular}

tained from the CBCT scans using NNT Viewer (QR srl) software via a direct volume rendering process. Then, the A point, the $\mathrm{B}$ point, and the nasion were identified by an examiner on the resultant lateral cephalogram. After selecting the File tab, the A point-nasion-B point (ANB) angle was calculated after manual dragging between the 3 points with point $\mathrm{N}$ (the nasion) as the vertex of the angle. Based on the ANB angle, the images were then categorized into those depicting class I, class II, and class III malocclusion. In total, 52 class I (ANB angle between $1^{\circ}$ to $4^{\circ}$ ), 66 class II (ANB angle $\geq 4^{\circ}$ ), and 62 class III (ANB angle $<1^{\circ}$ ) malocclusion cases were included in this study (Fig. 1). ${ }^{20}$

Next, the Frankfort plane was made parallel with the axial plane while the sagittal plane was aligned with the 

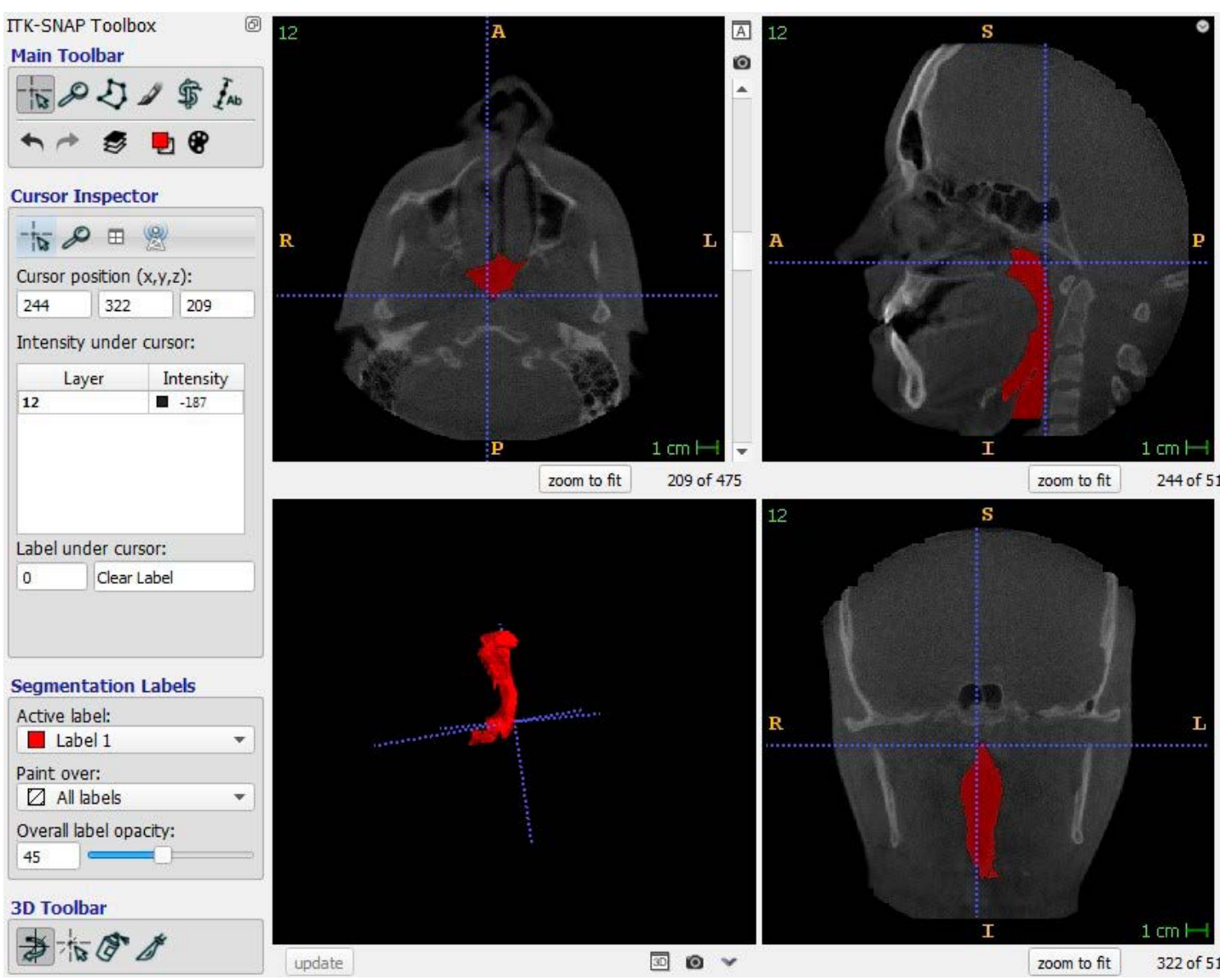

Fig. 3. A 3-dimensional model of the airway is reconstructed using ITK-SNAP software.

midline. The sagittal plane is the vertical line that passes through the ANS and the mid-posterior point of the spine termed the centrum. The Frankfort plane is the axial line that passes through the porion and orbitale points.

Eight linear and 2 angular hyoid bone parameters were measured (Fig. 2). The linear parameters included H-C3, H-EB, H-PNS, H-Me, H-X (the perpendicular distance from the hyoid bone to the vertical line passing through point $\mathrm{S}$ ), $\mathrm{H}-\mathrm{Y}$ (the perpendicular distance from $\mathrm{H}$ to the horizontal line passing through point $\mathrm{S}), \mathrm{H}-(\mathrm{C} 3-\mathrm{Me})$, and $\mathrm{C} 3-\mathrm{Me}$, while the angular parameters were $\mathrm{H}-\mathrm{S}-\mathrm{Ba}$ and $\mathrm{H}-\mathrm{N}-\mathrm{S}$. The points involved in these measurements are defined in Table 1.

Airway volume, total airway length, and upper airway length were measured using ITK-SNAP version 3.6.0 (Penn Image Computing and Science Laboratory, Philadelphia, PA, USA) software. Total airway length was defined as the distance between the hard palate and the base of the epiglottis. ${ }^{21}$ Upper airway length was measured as the distance between the upper border of the lower part of the pharynx and the point of minimum cross-sectional

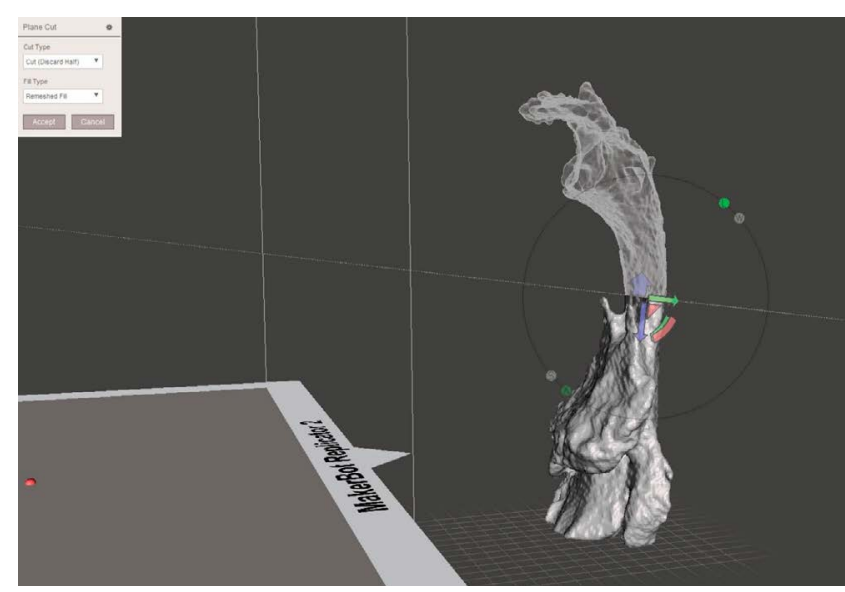

Fig. 4. The reconstructed model of airway is imported to Autodesk Meshmixer v. 3.0. Using the software's "plane cut" tool, the minimum cross-sectional area is marked manually and then calculated automatically.

area of the airway. Airway volume was defined as the anatomical space confined by 3 points (the hormion, PNS, and basion) and the line passing through the most antero- 
Table 2. Comparison of airway parameters in different classes of skeletal malocclusion

\begin{tabular}{|c|c|c|c|c|c|c|}
\hline Airway parameter & Skeletal class & $\mathrm{n}$ & Range & Mean & $F$ & $P$ value \\
\hline \multirow[t]{3}{*}{ Total airway length } & Class I & 52 & $55.7-85.4$ & $74.4 \pm 6.6$ & 1.94 & $P>0.05$ \\
\hline & Class II & 66 & $57.1-83.5$ & $74.7 \pm 6.0$ & & \\
\hline & Class III & 62 & $57.0-94.9$ & $75.2 \pm 8.7$ & & \\
\hline \multirow[t]{3}{*}{ Upper airway length } & Class I & 52 & $21.4-59.8$ & $36.6 \pm 7.0$ & 0.95 & $P>0.05$ \\
\hline & Class II & 66 & $18.1-59.4$ & $35.1 \pm 9.7$ & & \\
\hline & Class III & 62 & $22.6-38.2$ & $96.0 \pm 466.1$ & & \\
\hline \multirow[t]{3}{*}{ Volume } & Class I & 52 & $1091-7421$ & $2117.7 \pm 1201.6$ & 3.59 & $P<0.05$ \\
\hline & Class II & 66 & $1043-7421$ & $2107.8 \pm 844.7$ & & \\
\hline & Class III & 62 & $1009-9727$ & $2826.6 \pm 2505.3$ & & \\
\hline \multirow[t]{3}{*}{ Minimum cross-sectional area } & Class I & 52 & $1628.2-5983.2$ & $2886.2 \pm 835.4$ & 0.35 & $P>0.05$ \\
\hline & Class II & 66 & $1395.6-6183.6$ & $2814.7 \pm 1051.4$ & & \\
\hline & Class III & 62 & $1186.5-7846.7$ & $2978.0 \pm 1318.5$ & & \\
\hline \multirow[t]{3}{*}{ Mean cross-sectional area } & Class I & 52 & 14.6-129.9 & $28.9 \pm 19.3$ & 2.77 & $P>0.05$ \\
\hline & Class II & 66 & $14.9-129.9$ & $29.4 \pm 14.6$ & & \\
\hline & Class III & 62 & $14.1-153.2$ & $38.8 \pm 37.4$ & & \\
\hline \multirow[t]{3}{*}{ Morphology } & Class I & 52 & $15.5-255.0$ & $116.0 \pm 40.3$ & 0.89 & $P>0.05$ \\
\hline & Class II & 66 & $15.5-217.6$ & $106.0 \pm 45.5$ & & \\
\hline & Class III & 62 & $10.5-314.4$ & $117.6 \pm 64.5$ & & \\
\hline \multirow[t]{3}{*}{ Location } & Class I & 52 & $0.3-0.8$ & $0.4 \pm 0.0$ & 0.92 & $P>0.05$ \\
\hline & Class II & 62 & $0.3-48.6$ & $1.2 \pm 5.9$ & & \\
\hline & Class III & 66 & $0.2-0.7$ & $0.4 \pm 0.1$ & & \\
\hline
\end{tabular}

superior point of $\mathrm{C} 4$ and the posterior wall of the pharynx, parallel to the Frankfort plane. ${ }^{22}$

Using this program, a 3D model of the airway was designed (Fig. 3). This model was subsequently used as raw data to calculate the minimum cross-sectional area of the airway using Autodesk Meshmixer v. 3.0 (Autodesk Inc., Mill Valley, CA, USA) software. By rotating the model spatially, the point of minimum cross-sectional area of the airway could be marked, and the area at that point could be calculated (Fig. 4).

Measurements were made by 2 observers (an oral and maxillofacial radiologist and a postgraduate student) twice each within a 2-week period. The images were viewed on a 20-inch monitor (LG, Seoul, Korea) in a semi-dark room, and the observers were allowed to change the contrast and brightness settings to optimize the viewing conditions as desired.

The collected data were entered into Excel software (Microsoft Corporation, Redmond, WA, USA) and were then imported into SPSS version 16 (SPSS Inc., Chicago, IL, USA) software for statistical analyses. Data were analyzed using analysis of variance followed by the Tukey post hoc test for multiple comparisons. The Pearson correlation test was applied to assess the correlations between the quantitative variables. All tests were conducted with $P<0.05$ considered to indicate statistical significance.

\section{Results}

The Cronbach alpha coefficient was calculated to assess the interobserver and intraobserver reliability. The levels of interobserver and intraobserver agreement were $>80 \%$.

A total of 180 CBCT scans of 118 women and 62 men were included in this study. They were divided into those depicting class I, class II, and class III malocclusion based on the ANB angle.

Table 2 shows the airway parameters measured in the different classes of skeletal malocclusion. Among the measured airway parameters, only the mean airway volume differed significantly among the 3 classes of malocclusion $(P<0.05)$, with the smallest and largest airway volumes 
Table 3. Comparison of hyoid parameters in different classes of skeletal malocclusion

\begin{tabular}{|c|c|c|c|c|c|c|}
\hline Hyoid parameter & Skeletal class & $\mathrm{n}$ & Range & Mean & $F$ & $P$ value \\
\hline \multirow[t]{3}{*}{$\mathrm{C} 3-\mathrm{Me}$} & Class I & 52 & $63.1-100.3$ & $76.7 \pm 8.3$ & & \\
\hline & Class II & 66 & $54.6-90.7$ & $72.8 \pm 8.0$ & 14.23 & $P<0.05$ \\
\hline & Class III & 62 & $63.1-94.9$ & $80.4 \pm 7.9$ & & \\
\hline \multirow[t]{3}{*}{$\mathrm{C} 3-\mathrm{H}$} & Class I & 52 & $22-45.1$ & $32.4 \pm 5.7$ & & \\
\hline & Class II & 66 & $3.5-42.8$ & $31.3 \pm 5.8$ & 4.24 & $P<0.05$ \\
\hline & Class III & 62 & $27.1-41.1$ & $34.0 \pm 3.7$ & & \\
\hline \multirow[t]{3}{*}{ H-EB } & Class I & 52 & 4.6-27.7 & $10.3 \pm 4.3$ & & \\
\hline & Class II & 66 & $5.1-28.1$ & $10.7 \pm 4.6$ & 12.58 & $P<0.05$ \\
\hline & Class III & 62 & $5.7-25.6$ & $14.0 \pm 4.2$ & & \\
\hline \multirow[t]{3}{*}{ H-PNS } & Class I & 52 & $41.5-72.2$ & $57.0 \pm 8.2$ & & \\
\hline & Class II & 66 & $41.8-77.3$ & $60.1 \pm 8.3$ & 6.55 & $P<0.05$ \\
\hline & Class III & 62 & $41.5-70.5$ & $55.2 \pm 6.9$ & & \\
\hline \multirow[t]{3}{*}{$\mathrm{H}-\mathrm{Me}$} & Class I & 52 & $29.8-63.5$ & $45.4 \pm 7.4$ & & \\
\hline & Class II & 66 & $26.8-57.9$ & $42.3 \pm 6.7$ & 9.42 & $P<0.05$ \\
\hline & Class III & 62 & $29.8-74.5$ & $47.9 \pm 7.8$ & & \\
\hline \multirow[t]{3}{*}{$\mathrm{H}-\mathrm{X}$} & Class I & 52 & $78.5-112.3$ & $94.7 \pm 9.0$ & & \\
\hline & Class II & 66 & 0-121.7 & $93.0 \pm 23.3$ & 0.18 & $P>0.05$ \\
\hline & Class III & 62 & $79.2-112.7$ & $93.6 \pm 8.4$ & & \\
\hline \multirow[t]{3}{*}{$\mathrm{H}-\mathrm{Y}$} & Class I & 52 & $0-68.4$ & $17.6 \pm 13.1$ & & \\
\hline & Class II & 66 & $2-45.2$ & $16.5 \pm 10.8$ & 0.20 & $P>0.05$ \\
\hline & Class III & 62 & $0-34.9$ & $17.6 \pm 10.7$ & & \\
\hline \multirow[t]{3}{*}{$\mathrm{H}-(\mathrm{C} 3-\mathrm{Me})$} & Class I & 52 & $0-31.8$ & $6.2 \pm 5.5$ & & \\
\hline & Class II & 66 & $0-14$ & $5.5 \pm 3.6$ & 0.61 & $P>0.05$ \\
\hline & Class III & 62 & $0-15.1$ & $6.3 \pm 3.5$ & & \\
\hline \multirow[t]{3}{*}{ H-S-BA } & Class I & 52 & $21.1-47.6$ & $37.6 \pm 6.0$ & & \\
\hline & Class II & 66 & $21.1-50.5$ & $34.8 \pm 6.0$ & 10.10 & $P<0.05$ \\
\hline & Class III & 62 & $29.1-58.8$ & $40.2 \pm 7.9$ & & \\
\hline \multirow[t]{3}{*}{$\mathrm{H}-\mathrm{N}-\mathrm{S}$} & Class I & 52 & $37.4-65.1$ & $53.0 \pm 5.4$ & & \\
\hline & Class II & 66 & $37.4-63.9$ & $52.7 \pm 5.2$ & 5.39 & $P<0.05$ \\
\hline & Class III & 62 & $44.1-89.5$ & $56.0 \pm 7.7$ & & \\
\hline
\end{tabular}

noted in patients with class II $\left(2107.8 \pm 844.7 \mathrm{~mm}^{3}\right)$ and class III $\left(2826.6 \pm 2505.3 \mathrm{~mm}^{3}\right)$ malocclusion, respectively. The Tukey test also showed that the mean airway volume among patients with class III malocclusion was significantly greater than that among those with class II malocclusion $(P<0.05)$. The nominal power was also calculated using the observed data. According to the analysis, the power of the tests for the effect sizes obtained for each variable was greater than 0.80 .

Table 3 includes the parameters related to hyoid bone po- sition in the different skeletal malocclusion classes. Using analysis of variance, significant differences were found in the mean values of C3-Me, C3-H, H-Eb, H-Me, H-S-Ba, $\mathrm{H}-\mathrm{N}-\mathrm{S}$, and H-PNS among the 3 classes $(P<0.05)$. Using the Tukey test, the mean values of $\mathrm{C} 3-\mathrm{H}, \mathrm{H}-\mathrm{Eb}, \mathrm{H}-\mathrm{S}$ $\mathrm{Ba}$, and $\mathrm{H}-\mathrm{N}-\mathrm{S}$ were determined to be significantly lower among patients with class II malocclusion than among those with class III malocclusion, while the mean value of H-PNS in class II malocclusion cases was significantly greater than that in cases of class III malocclusion. No sig- 
Table 4. Pearson correlation coefficients between airway and hyoid parameters in different classes of skeletal malocclusion

\begin{tabular}{|c|c|c|c|c|c|c|c|c|}
\hline \multirow[b]{2}{*}{$\begin{array}{c}\text { Hyoid } \\
\text { parameters }\end{array}$} & \multicolumn{8}{|c|}{ Airway parameters } \\
\hline & $\begin{array}{l}\text { Skeletal } \\
\text { class }\end{array}$ & $\begin{array}{l}\text { Airway } \\
\text { length }\end{array}$ & $\begin{array}{l}\text { Upper } \\
\text { airway } \\
\text { length }\end{array}$ & Volume & $\begin{array}{c}\text { Minimum } \\
\text { cross-sectional } \\
\text { area }\end{array}$ & Morphology & Location & $\begin{array}{c}\text { Mean } \\
\text { cross-sectional } \\
\text { area }\end{array}$ \\
\hline \multirow[t]{3}{*}{$\mathrm{C} 3-\mathrm{Me}$} & Class I & -0.05 & 0.22 & 0.10 & 0.18 & -0.15 & $0.28 *$ & 0.08 \\
\hline & Class II & $0.33^{*}$ & -0.01 & -0.15 & -0.09 & -0.003 & -0.01 & -0.18 \\
\hline & Class III & $-0.29 *$ & $-0.40 *$ & -0.03 & $-0.30 *$ & $-0.30^{*}$ & $-0.34 *$ & -0.003 \\
\hline \multirow[t]{3}{*}{$\mathrm{C} 3-\mathrm{H}$} & Class I & 0.14 & $0.53 *$ & 0.19 & $0.51 *$ & 0.14 & $0.53 *$ & 0.15 \\
\hline & Class II & $0.51 *$ & 0.02 & -0.16 & $0.33 *$ & $0.28 *$ & 0.02 & 0.21 \\
\hline & Class III & -0.04 & -0.17 & -0.001 & -0.086 & -0.11 & -0.19 & -0.003 \\
\hline \multirow[t]{3}{*}{ H-EB } & Class I & 0.20 & 0.24 & 0.05 & $0.36^{*}$ & $0.40 *$ & 0.16 & 0.03 \\
\hline & Class II & 0.20 & -0.02 & -0.03 & $-0.43 *$ & $-0.33 *$ & -0.02 & -0.01 \\
\hline & Class III & 0.04 & $0.35^{*}$ & 0.02 & $0.53 *$ & $0.460 *$ & $0.34 *$ & 0.03 \\
\hline \multirow[t]{3}{*}{ H-PNS } & Class I & $0.53 *$ & $0.28 *$ & $-0.28 *$ & 0.25 & $0.47 *$ & 0.03 & $-0.34 *$ \\
\hline & Class II & $0.60 *$ & 0.07 & 0.04 & $0.38 *$ & $0.34 *$ & 0.06 & -0.13 \\
\hline & Class III & $0.45^{*}$ & 0.02 & 0.24 & 0.02 & 0.02 & 0.15 & $-0.29 *$ \\
\hline \multirow[t]{3}{*}{ H-ME } & Class I & -0.23 & -0.08 & 0.03 & -0.12 & $-0.33 *$ & -0.02 & $-0.044 *$ \\
\hline & Class II & 0.01 & 0.02 & 0.02 & -0.15 & $-0.26 *$ & -0.02 & -0.003 \\
\hline & Class III & -0.23 & -0.24 & -0.01 & $-0.35^{*}$ & $-0.39 *$ & -0.18 & -0.02 \\
\hline \multirow{3}{*}{$\mathrm{H}-\mathrm{X}$} & Class I & $0.54 *$ & 0.28 & $-0.39 *$ & 0.25 & $0.58 *$ & 0.02 & $0.44 *$ \\
\hline & Class II & 0.01 & 0.06 & -0.10 & 0.07 & $0.27 *$ & 0.06 & -0.09 \\
\hline & Class III & $0.40^{*}$ & 0.03 & $-0.031 *$ & -0.04 & -0.24 & -0.12 & $-0.35^{*}$ \\
\hline \multirow[t]{3}{*}{$\mathrm{H}-\mathrm{Y}$} & Class I & 0.18 & $0.42 *$ & -0.01 & $0.33^{*}$ & 0.22 & $0.38 *$ & -0.04 \\
\hline & Class II & $0.51 *$ & 0.11 & 0.05 & $0.27 *$ & 0.23 & 0.11 & -0.12 \\
\hline & Class III & $0.39 *$ & 0.22 & -0.17 & 0.24 & $0.45^{*}$ & 0.08 & -0.20 \\
\hline \multirow[t]{3}{*}{$\mathrm{H}-\mathrm{C} 3-\mathrm{Me}$} & Class I & $-0.28 *$ & -0.01 & $0.30 *$ & 0.09 & 0.23 & 0.16 & $0.32 *$ \\
\hline & Class II & 0.09 & 0.11 & -0.13 & 0.22 & 0.19 & 0.11 & 0.18 \\
\hline & Class III & $0.39 *$ & 0.22 & -0.17 & 0.06 & $0.45^{*}$ & 0.08 & -0.20 \\
\hline \multirow[t]{3}{*}{ H-S-BA } & Class I & -0.14 & -0.01 & -0.02 & 0.10 & 0.16 & 0.08 & -0.03 \\
\hline & Class II & -0.05 & -0.001 & -0.07 & -0.01 & -0.03 & -0.001 & -0.04 \\
\hline & Class III & 0.03 & 0.10 & 0.06 & 0.06 & 0.12 & 0.13 & -0.06 \\
\hline \multirow[t]{3}{*}{$\mathrm{H}-\mathrm{N}-\mathrm{S}$} & Class I & 0.22 & 0.19 & 0.19 & 0.19 & $0.50 *$ & 0.09 & -0.26 \\
\hline & Class II & $0.26^{*}$ & -0.06 & -0.06 & -0.06 & $-0.27 *$ & -0.07 & 0.06 \\
\hline & Class III & -0.04 & $0.30^{*}$ & -0.12 & $0.34 *$ & $0.27 *$ & $0.37 *$ & -0.11 \\
\hline
\end{tabular}

*: $P<0.05$. All data provided are Pearson correlation coefficients ( $r$-values).

nificant differences were observed between the mean values of $\mathrm{H}-\mathrm{X}, \mathrm{H}-\mathrm{Y}$, and $\mathrm{H}-(\mathrm{C} 3-\mathrm{Me})$ among the 3 groups.

Table 4 shows the Pearson correlation coefficients for the correlations between the airway and hyoid parameters in the 3 malocclusion classes. Each of the airway parameters showed significant correlations with certain measurements of hyoid bone position; the significance of these correla- tions often differed according to the class of malocclusion, although some combinations of airway parameters and hyoid measurements lacked significant correlations across all 3 groups.

In patients with class I malocclusion, the airway volume was positively correlated with $\mathrm{H}-(\mathrm{C} 3-\mathrm{Me})$ and inversely correlated with H-PNS and H-X. The airway volume was 
similarly inversely correlated with H-X in class III malocclusion cases. No significant correlations were found between the airway volume and hyoid parameters in cases of class II malocclusion.

In all 3 malocclusion classes, $\mathrm{H}-\mathrm{Eb}$ was positively correlated with the minimum cross-sectional area and the airway morphology. H-PNS was also positively correlated with the total airway length. A significant positive correlation was additionally found between $\mathrm{H}-\mathrm{Y}$ and the total airway length in class II and class III malocclusion cases and between $\mathrm{H}-\mathrm{Y}$ and the upper airway length in class I malocclusion cases.

\section{Discussion}

Many studies have used lateral cephalograms to assess the correlations between airway dimensions and various skeletal patterns. $^{13-17}$

Reconstructed lateral cephalograms obtained from CBCT images were used in the present study. The reconstruction process, which is classified as a direct volume rendering technique, involves creating an image slice that represents a specific volume of the patient. Full-thickness volume rendering of images in the sagittal plane can be used to generate simulated skull projections, such as lateral cephalometric images. These reconstructed images lack magnification and parallax distortion. However, this technique involves use of the entire volumetric data set, and its interpretation is adversely affected by anatomic noise and the superimposition of multiple structures, issues that are also present in conventional projection radiography. ${ }^{23}$

Kaur et al. ${ }^{24}$ compared the reliability of lateral cephalography and computed tomography in the assessment of airway space and concluded that the measurements acquired from both modalities are reliable and reproducible, but computed tomography provides a better assessment of the cross-sectional dimensions of the airway.

The results of studies that used conventional lateral cephalograms to measure airway dimensions are consistent with those of the present study. For instance, in one study, the pharyngeal depth was found to be greater in patients with skeletal class III malocclusion than in patients with skeletal class I malocclusion. ${ }^{14}$

A study comparing the accuracy of linear measurements taken using lateral cephalograms obtained from CBCT scans with measurements taken using digital conventional lateral cephalometric radiography showed a statistically significant difference from the actual distance in lateral cephalometry for most linear measurements. In contrast, none of the landmarks on CBCT displayed a significant difference from the actual value. This indicates that $\mathrm{CBCT}$ seems to be more accurate than conventional lateral cephalometry. ${ }^{25}$

In cephalometry, anatomical structures are visualized on 2D images; such visualization is associated with issues including superimposition and asymmetric magnification, which make measurement more difficult. Asymmetric magnification occurs due to the projection geometry of lateral cephalometry. With this technique, exact superimposition of the right and left sides is impossible because the structures on the side nearer the image receptor are magnified less than the same structures on the side more distant from the receptor. ${ }^{23}$ The superimposition of structures is another unfavorable phenomenon that is inevitable with 2D imaging modalities.

CBCT is a rather recent technology that enables the $3 \mathrm{D}$ visualization of airway structures. It produces images without any superimposition or magnification. CBCT images have sub-millimeter resolution (0.076- to $0.125-\mathrm{mm}$ voxel resolution), ${ }^{23}$ which leads to higher image quality and facilitates the identification of anatomical landmarks and spaces.

Gribel et al. ${ }^{26}$ assessed the accuracy and reliability of craniometric measurements on lateral cephalograms and 3D measurements on CBCT scans. They concluded that CBCT craniometric measurements were accurate to a subvoxel size and can potentially be used as a quantitative diagnostic tool, while 2D cephalometric norms cannot be readily used for 3D measurements because of differences in accuracy between those measurements and the gold standard (direct measurement). In summary, CBCT is more useful than 2D imaging modalities for airway assessment and can serve as a strong diagnostic tool for this purpose.

Recently, a group of authors used CBCT to study the upper airway. ${ }^{4}$ Although magnetic resonance imaging has higher soft tissue resolution than CBCT, this imaging modality has key disadvantages of limited access and expensive equipment. ${ }^{27}$ Thus, in the present study, we used CBCT and ITK-SNAP and Meshmixer software programs to evaluate and study the airway morphology in different skeletal malocclusion classes. Of the airway parameters evaluated, only the airway volume differed significantly among the 3 types of skeletal malocclusion (Table 2). Class III and class II malocclusions were associated with the largest and smallest airway volumes, respectively, which could be the result of the horizontal position of the mandible affecting the position of the hyoid bone.

Jayaratne and Zwahlen ${ }^{28}$ assessed the CBCT scans of 62 
patients with skeletal class II or class III malocclusion to compare the anthropometric dimensions of the oropharyngeal airway in young adults. They performed volumetric, linear, and surface area measurements using $3 \mathrm{dMDvultus}$ software, in contrast to the ITK-SNAP software used in the present study. The airway borders were also outlined differently in the 2 studies. In the study by Jayaratne and Zwahlen, the superior border of the airway was defined as the horizontal line passing through the PNS parallel to the SN line, and the inferior border was defined as the line passing through the base of the epiglottis parallel to the SN line. In contrast, in the present study, the most inferior and superior borders were defined as the line passing through the most superior-anterior point of $\mathrm{C}_{4}$ and the line passing through the junction between the vomer and the sphenoid bone, respectively. Despite these differences, Jayaratne and Zwahlen reported that the mean airway volume in patients with class III malocclusion was significantly larger than that in patients with class II malocclusion, which was consistent with the results of our study.

In a study by Kim et al., ${ }^{29}$ the cross-sectional area and the volume of the airway were measured in 27 children with a mean age of 11 years using CBCT. The authors reported that the total airway volume (including the nasal cavity, nasopharynx, and oropharynx) was significantly smaller in retrognathic children than in the group with normal craniofacial growth. However, the volume of the lower structures was not significantly different between the 2 groups. Similarly, some other studies have reported significantly smaller airway volume in patients with class II malocclusion than in those with other classes of skeletal malocclusion. ${ }^{10,30}$

Iwasaki et al. ${ }^{31}$ examined the oropharyngeal airway in 20 children with class III malocclusion and 25 children with class I malocclusion. They reported that children with class III malocclusion had significantly larger airway cross-sectional areas than children with class I malocclusion. They also found that the cross-sectional area of the airway was correlated with the severity of the class III malocclusion. Despite the difference in the ages of the participants (as subjects under 18 years of age were excluded from the present study), the results of Iwasaki et al. are consistent with those of the present report. The method of airway segmentation was similar across the 2 studies; however, we did not calculate the volume of the nasal cavity.

It can be inferred that in class III malocclusions, the mandible is positioned anteriorly, and therefore, the muscles and ligaments attached to the jaw cause similar anterior positioning of the hyoid bone; consequently, the airway dimensions increase.
The results of the present study revealed significant differences in the hyoid parameters of C3-H, H-Eb, H-PNS, $\mathrm{H}-\mathrm{Me}, \mathrm{H}-\mathrm{S}-\mathrm{Ba}$, and $\mathrm{H}-\mathrm{NS}$ among different classes of skeletal malocclusion. In the present study, the mean values of C3-Me and $\mathrm{C} 3-\mathrm{H}$ in patients with class II malocclusion were smaller than the corresponding values in the other groups. Mortazavi et al..$^{32}$ and Bedoya et al. ${ }^{33}$ similarly reported that the $\mathrm{C} 3-\mathrm{H}$ distance was significantly smaller in class II patients than in the other groups.

Lakshmi et al. ${ }^{34}$ assessed the pharyngeal width and growth pattern in different classes of skeletal malocclusion. They reported that airway width, as assessed on 60 lateral cephalograms, was significantly different in class I and class II patients. In our study, however, no significant difference in this parameter was observed among the malocclusion classes.

Based on our findings, the H-Me distance was inversely correlated with the minimum cross-sectional area in patients with class III malocclusion. In fact, a reduction in hyoid-to-mandibular symphysis (Me) distance was associated with an increase in the minimum cross-sectional area of the airway. Moreover, H-PNS was correlated with airway length in all 3 malocclusion classes.

Jiang $^{12}$ assessed correlations between the position of the hyoid bone and airway dimensions in 254 Chinese adolescents using CBCT. The age range of the patients and the software program (MIMICS) used to analyze the parameters in that study differed from those in the present study. However, Jiang measured the same hyoid and airway parameters as in the present study. In the study by Jiang, ${ }^{12}$ the airway length, width, and volume were found to be positively correlated with $\mathrm{H}-\mathrm{Me}, \mathrm{H}-(\mathrm{C} 3-\mathrm{Me}), \mathrm{H}-\mathrm{Y}, \mathrm{C} 3-$ $\mathrm{Me}, \mathrm{C} 3-\mathrm{H}$, and H-PNS and to be inversely correlated with $\mathrm{H}-\mathrm{S}-\mathrm{Ba}$ and $\mathrm{H}-\mathrm{Eb}$. The $\mathrm{H}-\mathrm{X}$ and $\mathrm{H}-\mathrm{Eb}$ measurements were inversely correlated with the airway volume, the minimum and mean cross-sectional area, and the anteroposterior and mediolateral diameters. However, in the present study, the airway volume was found to be inversely correlated with H-PNS in patients with class I malocclusion, and H-PNS was significantly correlated with most of the other airway parameters.

A supine CBCT scanner was used in the present study based on the fact that the soft palate epiglottis and the entrance of the esophagus move caudally when the patient's position changes from supine to upright and move posteriorly when that position changes from upright to supine. The hyoid bone moves caudally but not posteriorly in response to the same changes in position. ${ }^{28}$ Therefore, the calculated airway dimensions in our study may differ 
from the corresponding values in other studies that used upright or seating CBCT scanners; however, since the findings were assessed comparatively, this would not affect the final results.

One major limitation of the present study was patient collection based on our inclusion criteria. Large field-ofview CBCT is mostly ordered for patients after orthognathic surgery, for those with cleft lips or palates, or for those who have undergone major orthodontic treatment; however, such cases were excluded from the study, since their normal anatomy had been altered. Many additional patients were also excluded because of poor CBCT image quality. Another limitation of this study related to the use of software programs such as ITK-SNAP. In order to design the 3D airway model in ITK-SNAP, all of the borders had to be dragged by the examiner, and the software then automatically filled the confined area based on a predetermined algorithm. However, in some cases, voids and extra spots were present in the extracted model due to software bugs. These voids were repaired and filled, and the extra points were erased manually by the examiner, in a process that was complex and time-consuming. Designing software specifically for airway measurements can address this problem.

In conclusion, the positioning of the hyoid bone and the anteroposterior jaw affected the airway dimensions and should be taken into account during orthognathic surgery. This particularly applies to the mandibular setback surgery of patients with class III malocclusion, as this procedure results in posterior movement of the hyoid bone and can constrict the airway. Due to the risk of sleep apnea and airway obstruction, the airway condition in such patients should be evaluated prior to any surgical intervention to prevent unwanted complications.

\section{Acknowledgments}

The present paper is derived from a thesis with reference number: 9609285938 , which is conducted in research and technology center of Hamadan university of medical sciences.

\section{Conflicts of Interest: None}

\section{References}

1. Nejaim Y, Aps JK, Groppo FC, Haiter Neto F. Evaluation of pharyngeal space and its correlation with mandible and hyoid bone in patients with different skeletal classes and facial types. Am J Orthod Dentofacial Orthop 2018; 153: 825-33.

2. Bartolucci ML, Bortolotti F, Raffaelli E, D'Anto V, Michelotti A, Alessandri Bonetti G. The effectiveness of different mandibular advancement amounts in OSA patients: a systematic review and meta-regression analysis. Sleep Breath 2016; 20: 911-9.

3. Choi JK, Hur YK, Lee JM, Clark GT. Effects of mandibular advancement on upper airway dimension and collapsibility in patients with obstructive sleep apnea using dynamic upper airway imaging during sleep. Oral Surg Oral Med Oral Pathol Oral Radiol Endod 2010; 109: 712-9.

4. Gong X, Li W, Gao X. Effects of craniofacial morphology on nasal respiratory function and upper airway morphology. $\mathbf{J}$ Craniofac Surg 2018; 29: 1717-22.

5. Memon S, Fida M, Shaikh A. Comparison of different craniofacial patterns with pharyngeal widths. J Coll Physicians Surg Pak 2012; 22: 302-6.

6. Nazarali N, Altalibi M, Nazarali S, Major MP, Flores-Mir C, Major PW. Mandibular advancement appliances for the treatment of paediatric obstructive sleep apnea: a systematic review. Eur J Orthod 2015; 37: 618-26.

7. Claudino LV, Mattos CT, Ruellas AC, Sant' Anna EF. Pharyngeal airway characterization in adolescents related to facial skeletal pattern: a preliminary study. Am J Orthod Dentofacial Orthop 2013; 143: 799-809.

8. Niiranen TJ, Kronholm E, Rissanen H, Partinen M, Jula AM. Self-reported obstructive sleep apnea, simple snoring, and various markers of sleep-disordered breathing as predictors of cardiovascular risk. Sleep Breath 2016; 20: 589-96.

9. Wessendorf TE, Thilmann AF, Wang YM, Schreiber A, Konietzko N, Teschler H. Fibrinogen levels and obstructive sleep apnea in ischemic stroke. Am J Respir Crit Care Med 2000; 162: 2039-42.

10. El H, Palomo JM. Airway volume for different dentofacial skeletal patterns. Am J Orthod Dentofacial Orthop 2011; 139: e511-21.

11. Riepponen A, Myllykangas R, Savolainen J, Kilpeläinen P, Kellokoski J, Pahkala R. Changes in posterior airway space and hyoid bone position after surgical mandibular advancement. Acta Odontol Scand 2017; 75: 73-8.

12. Jiang YY. Correlation between hyoid bone position and airway dimensions in Chinese adolescents by cone beam computed tomography analysis. Int J Oral Maxillofac Surg 2016; 45: 914-21.

13. Chokotiya H, Banthia A, K SR, Choudhary K, Sharma P, Awasthi N. A study on the evaluation of pharyngeal size in different skeletal patterns: a radiographic study. J Contemp Dent Pract 2018; 19: 1278-83.

14. Dobrowolska-Zarzycka M, Dunin-Wilczynska I, Mitura I, Dabala M. Evaluation of upper airways depth among patients with skeletal Class I and III. Folia Morphol (Warsz) 2013; 72: 155-60.

15. Flores-Blancas AP, Carruitero MJ, Flores-Mir C. Comparison of airway dimensions in skeletal class I malocclusion subjects with different vertical facial patterns. Dental Press J Orthod 2017; 22: 35-42.

16. Sahoo NK, Jayan B, Ramakrishna N, Chopra SS, Kochar G. Evaluation of upper airway dimensional changes and hyoid 
position following mandibular advancement in patients with skeletal class II malocclusion. J Craniofac Surg 2012; 23: e623-7.

17. Uslu-Akcam O. Pharyngeal airway dimensions in skeletal class II: a cephalometric growth study. Imaging Sci Dent 2017; 47: 1-9.

18. Shokri A, Shakibaei Z, Langaroodi AJ, Safaei M. Evaluation of the mandibular canal visibility on cone-beam computed tomography images of the mandible. J Craniofac Surg 2014; 25: e273-7.

19. Chauhan A, Autar R, Pradhan KL, Yadav V. Comparison of pharyngeal airway dimension, tongue and hyoid bone position based on ANB angle. Natl J Maxillofac Surg 2015; 6: 42-51.

20. Proffit WR, Fields HW, Sarver DM. Contemporary orthodontics. 5th ed. St. Louis: Mosby/Elsevier; 2013. p. 190-6.

21. Genta PR, Schorr F, Eckert DJ, Gebrim E, Kayamori F, Moriya HT, et al. Upper airway collapsibility is associated with obesity and hyoid position. Sleep 2014; 37: 1673-8.

22. Shokri A, Miresmaeili A, Ahmadi A, Amini P, Falah-Kooshki S. Comparison of pharyngeal airway volume in different skeletal facial patterns using cone beam computed tomography. J Clin Exp Dent 2018; 10: e1017-28.

23. Mallya SM, Lam EW, Elsevier. White and Pharoah's oral radiology: principles and interpretation. 8th ed. St. Louis: Elsevier; 2019.

24. Kaur S, Rai S, Kaur M. Comparison of reliability of lateral cephalogram and computed tomography for assessment of airway space. Niger J Clin Pract 2014; 17: 629-36.

25. Shokri A, Khajeh S, Khavid A. Evaluation of the accuracy of linear measurements on lateral cephalograms obtained from cone-beam computed tomography scans with digital lateral cephalometric radiography: an in vitro study. J Craniofac Surg 2014; 25: 1710-3.

26. Gribel BF, Gribel MN, Frazäo DC, McNamara JA Jr, Manzi FR. Accuracy and reliability of craniometric measurements on lateral cephalometry and 3D measurements on CBCT scans. Angle Orthod 2011; 81: 26-35.

27. Chen H, Aarab G, Parsa A, de Lange J, van der Stelt PF, Lobbezoo F. Reliability of three-dimensional measurements of the upper airway on cone beam computed tomography images. Oral Surg Oral Med Oral Pathol Oral Radiol 2016; 122: 104-10.

28. Jayaratne YS, Zwahlen RA. The oropharyngeal airway in young adults with skeletal class II and class III deformities: a 3-D morphometric analysis. PLoS One 2016; 11: e0148086.

29. Kim YJ, Hong JS, Hwang YI, Park YH. Three-dimensional analysis of pharyngeal airway in preadolescent children with different anteroposterior skeletal patterns. Am J Orthod Dentofacial Orthop 2010; 137: 306. e1-11.

30. Grauer D, Cevidanes LS, Styner MA, Ackerman JL, Proffit WR. Pharyngeal airway volume and shape from cone-beam computed tomography: Relationship to facial morphology. Am J Orthod Dentofacial Orthop 2009; 136: 805-14.

31. Iwasaki T, Hayasaki H, Takemoto Y, Kanomi R, Yamasaki Y. Oropharyngeal airway in children with class III malocclusion evaluated by cone-beam computed tomography. Am J Orthod Dentofacial Orthop 2009; 136: 318. e1-9.

32. Mortazavi S, Asghari-Moghaddam H, Dehghani M, Aboutorabzade M, Yaloodbardan B, Tohidi E, et al. Hyoid bone position in different facial skeletal patterns. J Clin Exp Dent 2018; 10: e346-51.

33. Bedoya A, Landa Nieto Z, Zuluaga LL, Rocabado M. Morphometry of the cranial base and the cranial-cervical-mandibular system in young patients with type II, division 1 malocclusion, using tomographic cone beam. Cranio 2014; 32: 199207.

34. Lakshmi KB, Yelchuru SH, Chandrika V, Lakshmikar OG, Sagar VL, Reddy GV. Comparison between growth patterns and pharyngeal widths in different skeletal malocclusions in south Indian population. J Int Soc Prev Community Dent 2018; 8: 224-8. 